\title{
Breast Cancer Metastatic Relapse in Young Moroccan Women According to Prognostic Factors (A Study about 60 Cases)
}

Benlghazi Abdelhamid $^{1 *}$, Belouad Moad ${ }^{1}$, Saad Benali ${ }^{1}$, Aitbouhou Rachid ${ }^{1}$, Kouach Jawad ${ }^{1}$

${ }^{1}$ Department of Gynecology - Obstetrics, Mohammed V Military teaching Hospital, Faculty of Medicine and Pharmacy, Mohammed V University in Rabat, Morocco

DOI: $10.36348 /$ sijog.2021.v04i04.008

| Received: 08.03.2021 | Accepted: 14.04.2021 | Published: 19.04.2021

*Corresponding author: Benlghazi Abdelhamid

\section{Abstract}

The objective of this work is to clarify by a retrospective study the prognostic parameters of breast cancer in young Moroccan women and to clarify the epidemiological histological and prognostic characteristics in a subgroup that have a metastatic relapse in order to determine the impact of the different prognostic factor on overall survival. During a period of 5 years, from January 2010 to December 2015, 325 women suffering from breast cancer were counted at the Radiotherapy Department of the Mohammed V Military Hospital of Instruction. Among them, 60 were aged 40 years and under. In our series, patients were followed up until April 2018, 13 cases of metastatic relapses were recorded, i.e. 21.7\% of cases. In a single-factor study, the prognostic parameters were mean consultation time, age, family history of breast cancer, tumor size, histological type, number of lymph nodes invaded, lymphatic embolism, SBR grade, hormone receptor, and herecept-test status. The overall survival rate of all patients was $92,1 \%$ at 3 years and $88,9 \%$ at 5 years. Multifactorial analysis isolated 3 prognostic parameters: initial tumor size, the number of lymphaitic gonglion invaded and the molecular type.

Keywords: Breast cancer, young women,metastatic relaps, Prognostic factors, Survival, Morocco.

Copyright () 2021 The Author(s): This is an open-access article distributed under the terms of the Creative Commons Attribution 4.0 International License (CC BY-NC 4.0) which permits unrestricted use, distribution, and reproduction in any medium for non-commercial use provided the original author and source are credited.

\section{INTRODUCTION}

Breast cancer is the most common cancer in women worldwide, and its incidence continues to rise despite scientific advances in diagnosis and treatment.

In the scientific literature, there are several definitions of young age in breast cancer: $<35,<40,<50$ or premenopausal. Women under 35 and under 40 share the same tumour characteristics and have a similar prognosis, while women aged 40-49 have a better survival rate, so a threshold at 50 years will dilute the differences[1].

Early-onset of breast cancer (under the age of 40) represents only $7 \%$ of all breast cancers, but is the most common cancer in this age group in women. It is also known to be of worse prognosis, with a more aggressive tumoral behavior. The interaction of different prognostic factors contributes to the complexity of this population: tumor burden and biological features (using classical histopronostic features and genomic data) show differences from older women.

According to the majority of authors, breast cancer in young women has its own epidemiological, diagnostic and also prognostic characteristics, going so far as to consider youth as a pejorative prognostic factor.

The objective of our study is to analyse overall survival, relapse-free survival and prognostic factors related to metastatic breast cancer relapse in young women. Through a retrospective study carried out at the gynaecological-obstetrical and radiotherapy departments of the Mohamed V military hospital.

\section{MATERIALS \& METHODOLOGY Materials}

From 1st January 2010 to 31st December 2015,325 patients were treated for breast cancer by the oncology-radiotherapy department of the Mohammed V Military Hospital of Instruction in Rabat. 
Methods

- This is a 5-year retrospective study of breast cancer cases in young women aged 40 and under who meet the following criteria:

- Inclusion Criteria:

- Women aged 40 and under at the time of diagnosis.

- Histologically confirmed diagnosis of breast cancer.

- First, we screened the files to highlight those related to breast cancer in women of any age.

- Next, we selected the files of young patients aged 40 and under who met our inclusion criteria. An operation sheet was duly completed for each of them.

- In a second step, the SPSS software was used for the statistical analyses. The data were processed in percentages, averages or medians.

- The tumour was classified using the TNM 7th edition 2010 classification.

- Patient follow-up has been extended until April 2018.

- Survival was calculated according to the Kaplan-Meier method, taking the date of diagnosis of breast cancer as the date of origin.

- Data collection was carried out with respect for the anonymity of the patients and the confidentiality of their information.

\section{RESULTS}

During a period of 5 years, from January 2010 to December 2015, 325 women suffering from breast cancer were counted at the Radiotherapy Department of the Mohammed V Military Hospital of Instruction. Among them, 60 were aged 40 years and under; a rate of $18.46 \%$.

\section{1-Follow-up and monitoring}

In our series, patients were followed up until April 2018. The median follow-up was 46 (27-62) months with extremes of 3 and 99 months.

During this period, patients were monitored every 3-6 months for the first 3 years after the end of treatment, then every 6 months for the next 2 years and once a year for the rest of the patient's life by means of mammography, chest X-ray and abdominal ultrasound depending on clinical signs.

\section{2-Relapses}

No locoregional relapses were noted in our series. 13 cases of metastatic relapses were recorded, i.e. $21.7 \%$ of cases.

The most frequent metastatic site was bone with $61.5 \%$ of cases (Table I).

The median time to metastatic relapse is 12 (6-29) months.

Table-I: Distribution of patients according to metastasis sites

\begin{tabular}{|l|l|l|}
\hline Metastasis site & Number & Percentage (\%) \\
\hline Bone & 8 & 61,5 \\
\hline Liver & 1 & 7,7 \\
\hline Lung & 1 & 7,7 \\
\hline Brain & 1 & 7,7 \\
\hline Liver + bone & 1 & 7,7 \\
\hline Bone + Brain & 1 & 7,7 \\
\hline Total & 13 & $100 \%$ \\
\hline
\end{tabular}

3-Metastatic relapse according to prognostic factors

The average age of our patients was about 34 years with extremities of 32 and 40,5 patients have a family history of breast cancer ,relapse is predominant in patients with a tumour size more than $2 \mathrm{~cm}$, the ductal carcinoma infiltrant(DCI)currently known as non-specific invasive carcinoma, was the only histological type in all patients.

We note a predominance of relapse cases in patients with an SBR II grade with a percentage of $69.2 \%$. Tumour emboli were present in 9 patients with a rate of $69.2 \%$; $50 \%$ had 4 positive lymph nodes or more.

The search for hormone receptors (HR) was conducted in 13 patients. These estrogen receptors (ER) and progesterone (PR) was both positive in $60.2 \%$ of cases, dissociated in $23.1 \%$ and negative in $16.7 \%$.

The hercept test was performed in all patients by immunohistochemistry technique, supplemented by FISH or CISH method in the case of HER2 score $(2+), 76.9 \%$ of patients with systemic relapse have a negative HERCEPT test. 
Table-II: Distribution of cases of relapse according to prognostic factors

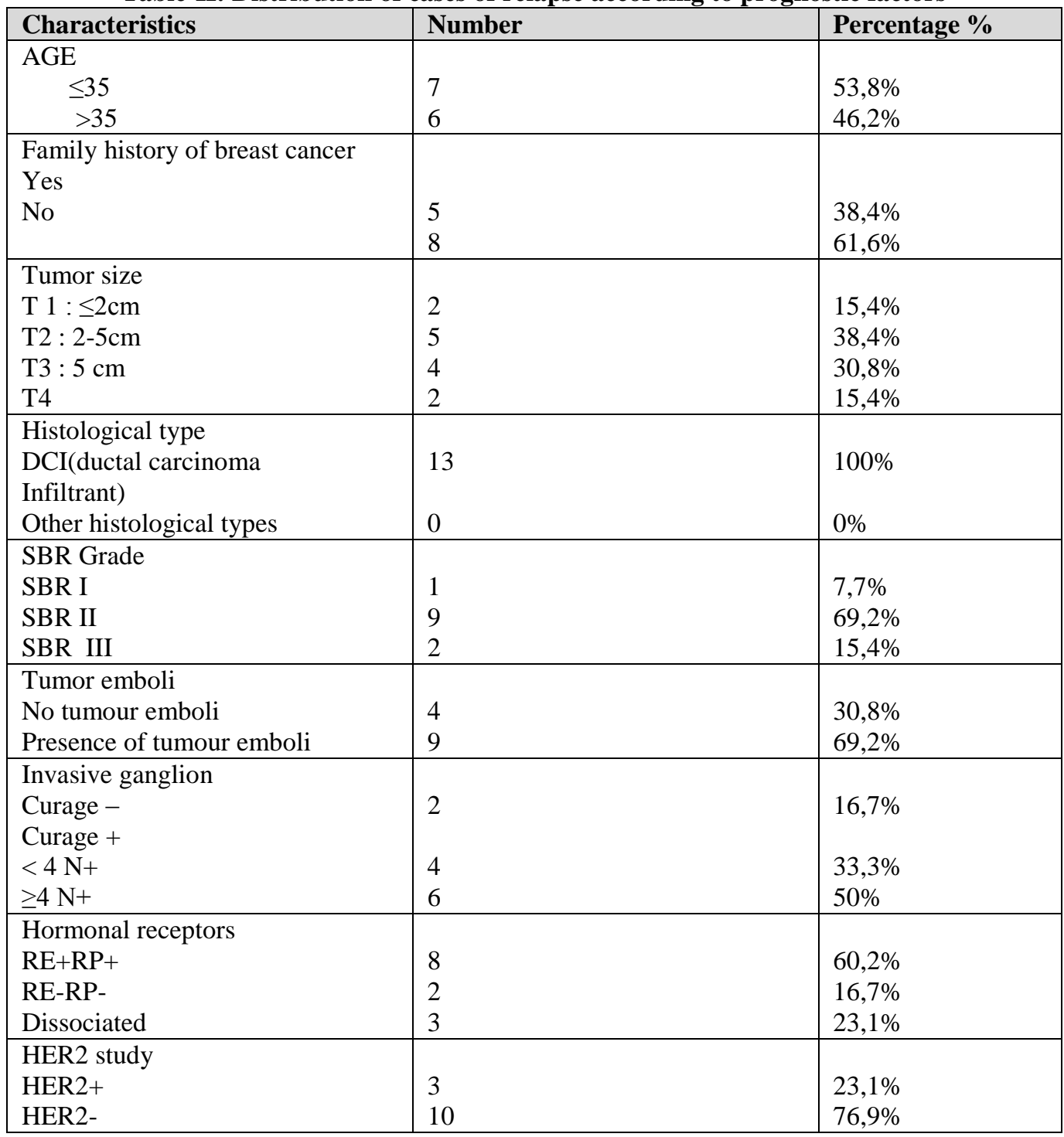

\section{4-Survival}

In order to better assess relapse-free survival and overall survival, we tried to contact all the patients who had disappeared after the end of the treatment, 10 of them remained unreachable, i.e. a rate of $16.7 \%$. Thus, $75 \%$ of the patients were alive, while $8.3 \%$ had died. (Table III) Survival was calculated according to the Kaplan-Meier method.

Table-III: Distribution of patients according to their evolution

\begin{tabular}{|l|l|l|}
\hline Patient Survival & Patients & Percentage \% \\
\hline Alive & 45 & $75 \%$ \\
\hline Deceased & 5 & $8,3 \%$ \\
\hline Lost sight & 10 & $16,7 \%$ \\
\hline Total & 60 & $100 \%$ \\
\hline
\end{tabular}

a-Overall survival (SG)

The overall survival time has been calculated from the date of diagnosis of breast cancer to the date of death or last visit. The rate of OS at 3 years is $92.1 \%$ and it is $88.9 \%$ at 5 years (Figure 1).

The rate of $\mathrm{SG}$ at 3 years is $87 \%$ among women aged 35 and under, while it is $96.4 \%$ among women aged 36-40. (Figure 2) b-Survival without relapse (SRH).

Relapse-free survival time was calculated from the date of diagnosis to the date of the occurrence of the event (the relapse) or the date of the last consultation.

The SRH rate at 3 years is $94.2 \%$, so it is $91 \%$ at 5 years (Figure 3 ) 


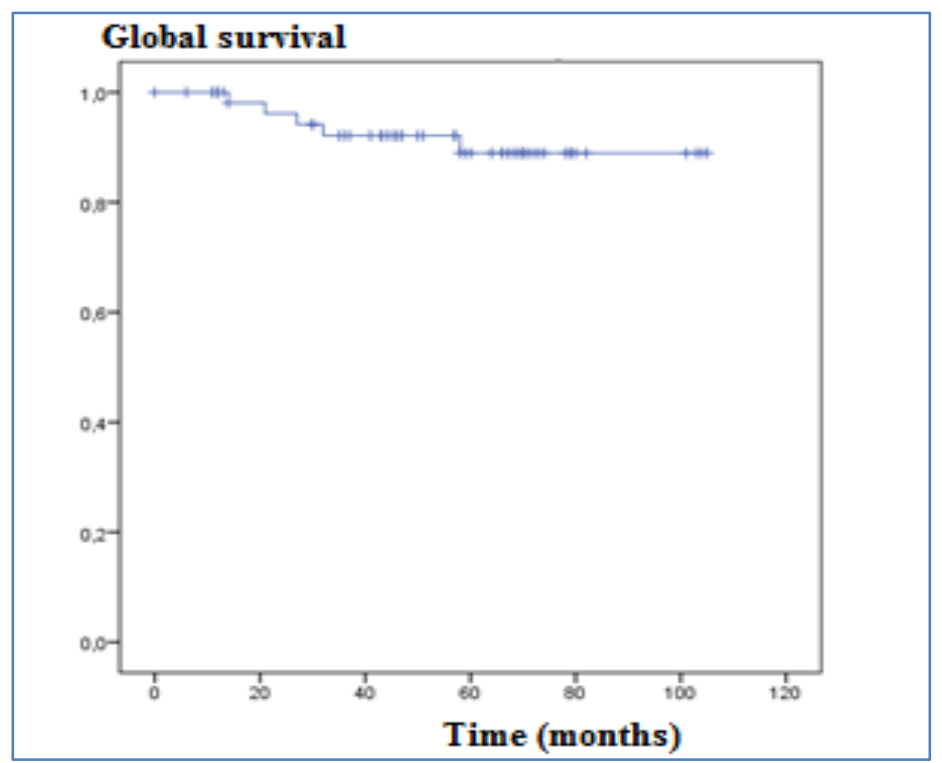

Fig-1: Global survival curve according to Kaplan-Meier

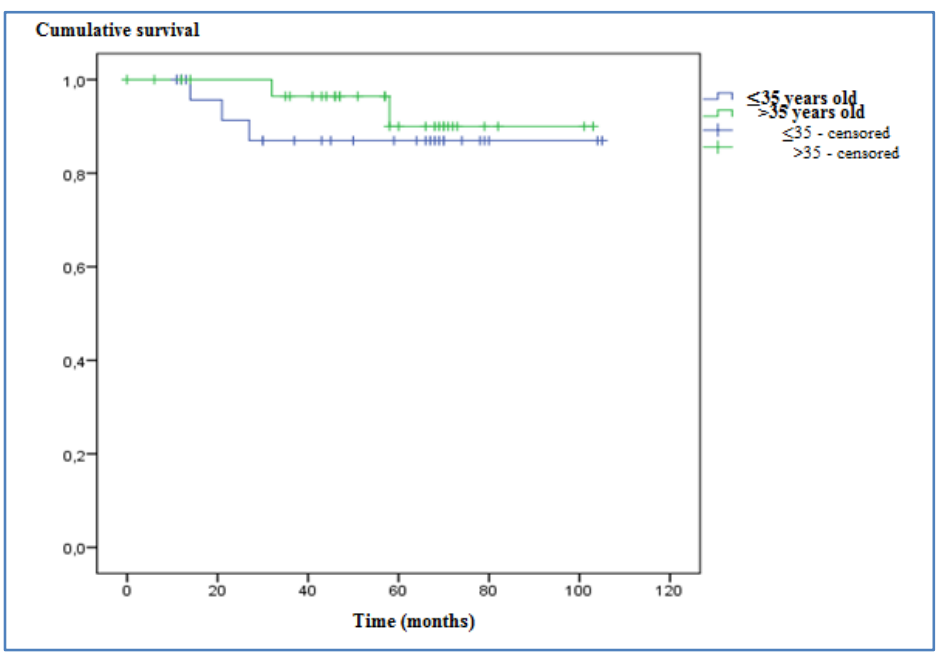

Fig-2: Overall survival curve as a function of age groups

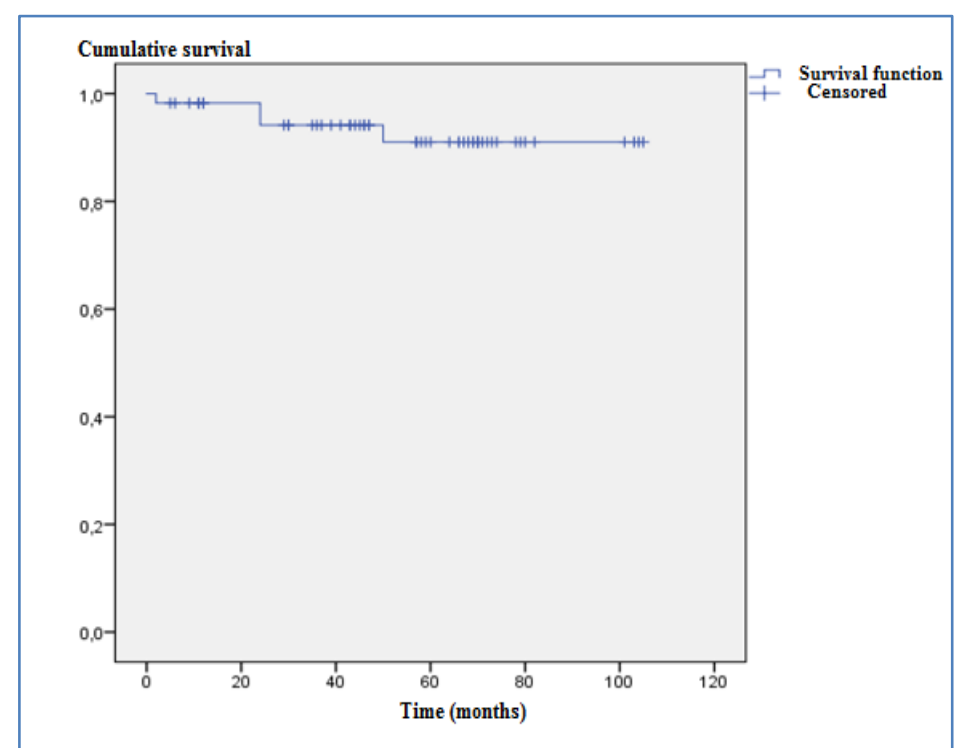

Fig-3: Relapse-free survival curve according to Kaplan-Meier 


\section{DISCUSSION}

Young age is a pejorative prognostic factor found in all series, but whose specific role is modulated by confounding factors, sometimes difficult to identify due to the retrospective nature of most of these analyzes. Beyond histopronostic and molecular peculiarities in this age group, the specific influence young age is discussed and the data come mainly from registers. The most important series is that from Japanese register covering 25,898 women treated from 2004 to 2006 confirming the prognostic impact of age ( $<35$ years vs $35-50$ vs $>50$ years), to the detriment of the youngest patients[2] The unfavorable influence of young age ( $<35$ years) is found after adjustment for other factors $(\mathrm{T}, \mathrm{N}$, histological subtype, adjuvant treatment) with a Hazard Ratio (HR) of 1.73 for the risk of recurrence, $\mathrm{HR}=1.52$ for the risk of death from cancer and $\mathrm{HR}=1.58$ for overall mortality.

Young age at diagnosis of breast cancer may suggest presence of predisposing genetic variation. Literature includes multiple studies of the frequency of variations pathogens, including BRCA1 and BRCA2. Tung et al. at 180 women with breast cancer before age 45 , identified 15 deleterious variations of BRCA1 $(8.3 \%)$ and 7 of BRCA2 (3.9\%)[3]. The presence family history increases the likelihood of identifying a deleterious mutation: $73 \%$ of carriers of deleterious variations had a family history of breast or ovarian cancer in Tung's study[3]. The frequency of mutation increases also with some characteristics like the character triple negative, $22 \%$ of triple negative breast cancers occurred with a BRCA1 mutation in the Copson series[4].

Several concordant studies have shown significantly that the size of the tumors was larger in patients youth. A link between age and tumor size has been demonstrated significant ( $\mathrm{p}<0.001)$ in an analysis of the Surveillance database, Epidemiology and End Results (SEER) between 1988 and 2003 on more of 200,000 patients[5], the percentage of T1 tumors was $38.6 \%$ in young women against $51.8 \%$ in patients older, the percentage of tumors between 2 and $5 \mathrm{~cm}$ (T2) is $40.2 \%$ among young women against $29.8 \%$ among womenolder. For T3 tumors, the percentage was $7.6 \%$ in young women and $4.6 \%$ in older women. More detailed but similar results, presented in a series of about 20,000 patients, published in 2009, show that T1a and $\mathrm{T} 1 \mathrm{~b}$ tumors are more common than female patients are over 40 years old while $\mathrm{T} 2$ and $\mathrm{T} 3$ tumors are more common in patients under 35 years of age and under 40 years of age[6].

We note significantly a lower frequency carcinomas in situ in young women with high rates reported $11.6 \%$ vs. $15.6 \%$ in older women in the SEER study[5].
There is also less invasive lobular carcinoma in young women $(0.8 \%$ vs $1.7 \%)$ than in older women in a study published in 2004 [7] and in the Italian series[8], as in the study published by Azim in 2015 [9].

The involvement of axillary lymph nodes in young women when compared with older patients is high[10]. A Nepali study with 944 breast cancer patients identified that axillary lymph nodes were positive in $73 \%$ of younger patients and $59 \%$ of older patients [11].These findings indicate the severity and aggressiveness of the disease in this age group.

We note significantly a higher number of grade III tumors in women youth. This rate is over $20 \%$ among young women compared to around $10 \%$ in older women in the study reported by Fredholm[6]; In the Danish study, the number of grade II or III varies by $63 \%$ in women younger than 35 years to $50 \%$ in women aged 45 to 49 years[12].

Hormone receptors are more often negative in young patients (28\% vs $14.2 \%)$ in the SEER database study[5] (23\% vs 13\%) in the Italian series[8].

For Partridge, the risk of death is doubled for Luminal A type cancers before 40 years compared to the age group 51-60 years $(\mathrm{HR}=2.1)$, while the $\mathrm{HR}$ is 1.4 for Luminal B-type forms and cancers triple negative and 1.2 for HER2 + forms[13]. However, in other series the Luminal B phenotype seems to be the most impacted by young age in terms of survival, as in the Fredholm series: age appears as a prognostic factor independent of specific 10-year survival respectively $69,76,84$ and $89 \%$ for the age groups <35 years / 3539 / 40-49 and 50-69 years[14]. For the women under 40 , the specific 10 -year survival is $75 \%$ for the Luminal B type (vs $92 \%$ for the Luminal A, 68 and $67 \%$ for HER2 + and triple negative cancers respectively).

The influence of hormone receptors in the forms of type Luminal (A or B) therefore seems attested, but the proper role of the statute receptors must be distinguished from that of targeting these receptors by hormone therapy. As such, the retrospective study by Sopik et al., women under 40-year-olds seem particularly penalized by the absence adjuvant hormone therapy with Tamoxifen: specific survival at 15 years of $50.4 \%$ in the absence of Tamoxifen vs. $68.1 \%$ in the adjuvant Tamoxifen[15].

For the triple negative cancers, the results of the literature are more contradictory, but do not eliminate the pejorative prognostic role of young age. Registry data Korean do not have an impact negative of young age on the overall survival of patients in the event of triple negative cancer[16] .Conversely, in the Cancello publication a unfavorable impact is observed for the age group $<35$ years[8]. 
The contradictions observed between these different studies may note differences in care, but also of the great heterogeneity of triple negative cancers.

Most prospective and retrospective series confirm the lack of impact of young age on the prognosis of HER2 + cancers. The data from the different registers will in this sense[16; 17].

The prognosis of $\mathrm{BC}$ in young women is generally considered less favorable. According to Chung et al. [18] survival without recidivism significantly appeared more low to five years for women under 40 compared to other age groups $(60.8 \%$ versus $73.2 \%$ for the 41 to 50 age group). For Lee et al.[19], the survival of women under 30 years of age was 10 to $20 \%$ lower compared to ones over 30 years.

Local relapses and metastases occur more frequently in young women than in older women[20]. According to Roche for dière et al., after five years, the relative risk of recurrence decreases less rapidly in young women[21].

According to Aryandono, death, recurrence and metastasis were higher in the younger group compared to elderly patients $(30.4 \%$ to $20 \% ; 7.95$ to $5.7 \%$ and $25 \%$ to $22.8 \%$ ). High proliferation rate and aggressiveness of tumor in the young patients seems to be the cause of this condition [22]. Looking at fiveyears survival rate, this survival rate was generally lower in younger patient compared with elderly patients in almost every prognostic factors. Breast cancer in elderly women lived longer than patients with young age $(158.11 \pm 104.97$ weeks compared to $142.08 \pm$ 95.47 weeks) and this was similar with the study of Grosclaude et al. [23].

However, the analysis of the largest series didnot show a significant difference in overall survival or survival without recidivism between women aged 30 or 40 and those aged ones while age under 35 years was a independent pejorative prognostic cause according toseveral authors [24].

\section{CONCLUSION}

Very young patients with breast cancer constitute a unique group of patients as they have special tumor characteristics. In the majority of studies, the pejorative pronostic role of young age is confirmed in analysis multivariate.

This group has more advanced presentation, with much more aggressive biologic behavior with an unfavorable impact from young age to diagnosis is found mainly for the shapes luminal type, in particular Luminal B, and has a significantly higher malignant axillary lymph node involvement. The role of age seems to be null in case of overexpression of HER2.
So, therapy for each young patient with breast cancer has to be evaluated carefully and individually, and the treatment strategies have to be tailored in a very precise manner.

\section{REFERENCES}

1. Fredholm, H. (2017). Breast cancer in young women: aspects on mortality and local recurrence.

2. Kataoka, A., Iwamoto, T., Tokunaga, E., Tomotaki, A., Kumamaru, H., Miyata, H., ... \& Tokuda, Y. (2016). Young adult breast cancer patients have a poor prognosis independent of prognostic clinicopathological factors: a study from the Japanese Breast Cancer Registry. Breast cancer research and treatment, 160(1), 163-172.

3. Tung, N., Lin, N. U., Kidd, J., Allen, B. A., Singh, N., Wenstrup, R. J., ... \& Garber, J. E. (2016). Frequency of germline mutations in 25 cancer susceptibility genes in a sequential series of patients with breast cancer. Journal of Clinical Oncology, 34(13), 1460.

4. Copson, E. R., Maishman, T. C., Tapper, W. J., Cutress, R. I., Greville-Heygate, S., Altman, D. G., ... \& Eccles, D. M. (2018). Germline BRCA mutation and outcome in young-onset breast cancer (POSH): a prospective cohort study. The lancet oncology, 19(2), 169-180.

5. Gnerlich, J. L., Deshpande, A. D., Jeffe, D. B., Sweet, A., White, N., \& Margenthaler, J. A. (2009). Elevated breast cancer mortality in women younger than age 40 years compared with older women is attributed to poorer survival in earlystage disease. Journal of the American College of surgeons, 208(3), 341-347.

6. Fredholm, H., Eaker, S., Frisell, J., Holmberg, L., Fredriksson, I., \& Lindman, H. (2009). Breast cancer in young women: poor survival despite intensive treatment. PloS one, 4(11), e7695.

7. Han, W., Kim, S. W., Park, I. A., Kang, D., Kim, S. W., Youn, Y. K., ... \& Noh, D. Y. (2004). Young age: an independent risk factor for diseasefree survival in women with operable breast cancer. BMC cancer, 4(1), 1-8.

8. Cancello, G., Maisonneuve, P., Rotmensz, N., Viale, G., Mastropasqua, M. G., Pruneri, G., ... \& Colleoni, M. (2010). Prognosis and adjuvant treatment effects in selected breast cancer subtypes of very young women $(<35$ years) with operable breast cancer. Annals of oncology, 21(10), 1974-1981.

9. Azim, H. A., Nguyen, B., Brohée, S., Zoppoli, G., \& Sotiriou, C. J. B. M. (2015). Genomic aberrations in young and elderly breast cancer patients, 13(1), 1-7.

10. Foo, C. S., Su, D., Chong, C. K., Chng, H. C., Tay, K. H., Low, S. C., \& Tan, S. M. (2005). Breast cancer in young Asian women: study on survival. ANZ journal of surgery, 75(7), 566-572.

11. Thapa, B., Singh, Y., Sayami, P., Shrestha, U. K., Sapkota, R., \& Sayami, G. (2013). Breast cancer 
in young women from a low risk population in Nepal. Asian Pacific Journal of Cancer Prevention, 14(9), 5095-5099.

12. Kroman, N., Tutt, A., Jensen, M. B., Wohlfahrt, J., Mouridsen, H. T., Andersen, P. K., ... \& Ross, G. (2000). Factors influencing the effect of age on prognosis in breast cancer: population based studyCommentary: much still to learn about relations between tumour biology, prognosis, and treatment outcome in early breast cancer. Bmj, 320(7233), 474-479.

13. Partridge, A. H., Hughes, M. E., Warner, E. T., Ottesen, R. A., Wong, Y. N., Edge, S. B., ... \& Tamimi, R. M. (2016). Subtype-dependent relationship between young age at diagnosis and breast cancer survival. Journal of Clinical Oncology, 34(27), 3308-3314.

14. Fredholm, H., Magnusson, K., Lindström, L. S., Garmo, H., Fält, S. E., Lindman, H., ... \& Fredriksson, I. (2016). Long-term outcome in young women with breast cancer: a populationbased study. Breast cancer research and treatment, 160(1), 131-143.

15. Sopik, V., Sun, P., \& Narod, S. A. (2017). The prognostic effect of estrogen receptor status differs for younger versus older breast cancer patients. Breast cancer research and treatment, 165(2), 391-402.

16. Ryu, J. M., Yu, J., Kim, S. I., Kim, K. S., Moon, H. G., Choi, J. E., ... \& Kim, S. W. (2017). Different prognosis of young breast cancer patients in their $20 \mathrm{~s}$ and $30 \mathrm{~s}$ depending on subtype: a nationwide study from the Korean Breast Cancer Society. Breast cancer research and treatment, 166(3), 833-842.

17. Liedtke, C., Rody, A., Gluz, O., Baumann, K., Beyer, D., Kohls, E. B., ... \& Karn, T. (2015). The prognostic impact of age in different molecular subtypes of breast cancer. Breast cancer research and treatment, 152(3), 667-673.

18. Chung, M., Chang, H. R., Bland, K. I., \& Wanebo, H. J. (1996). Younger women with breast carcinoma have a poorer prognosis than older women. Cancer: Interdisciplinary International Journal of the American Cancer Society, 77(1), 97-103.

19. Lee, C. G., McCormick, B., Mazumdar, M., Vetto, J., \& Borgen, P. I. (1992). Infiltrating breast carcinoma in patients age 30 years and younger: long term outcome for life, relapse, and second primary tumors. International Journal of Radiation Oncology* Biology* Physics, 23(5), 969-975.

20. Tuma, R. S. (2005). Trastuzumab trials steal show at ASCO meeting. Journal of the National Cancer Institute, 97(12), 870-871.

21. De La Rochefordiere, A., Campana, F., Fenton, J., Vilcoq, J. R., Fourquet, A., Asselain, B., ... \& Magdelenat, H. (1993). Age as prognostic factor in premenopausal breast carcinoma. The Lancet, 341(8852), 1039-1043.

22. Aryandono, T., Harijadi, S., \& Soeripto, S. (2006). Breast cancer in young women: prognostic factors and clinicopathological features. Asian Pacific Journal of Cancer Prevention, 7(3), 451.

23. Grosclaude, P., Colonna, M., Hedelin, G., Tretarre, B., Arveux, P., Lesec'h, J. M., ... \& Sauvage-Machelard, M. (2001). Survival of women with breast cancer in France: variation with age, stage and treatment. Breast cancer research and treatment, 70(2), 137-143.

24. Foxcroft, L. M., Evans, E. B., \& Porter, A. J. (2004). The diagnosis of breast cancer in women younger than 40. The breast, 13(4), 297-306. 